\title{
CÉLULAS DEL SISTEMA INMUNITARIO ADQUIRIDO
}

\section{CELLS OF THE SYSTEM ACQUIRED INMUNITARIO}

\author{
Mamani-Cahuata Luz ${ }^{1 *}$ Mercado-Mamani Sively ${ }^{2}$ Mercado-Portal Jorge $^{3}$ Laquihuanaco-Loza Felipe $^{4}$ \\ Tapia-Condori Rildo ${ }^{5}$ Heredia-Veloz David ${ }^{6}$ \\ ${ }^{1}$ Doctora en Salud Pública, Especialista en Rehabilitación Oral, Docente de la Universidad Nacional del Altiplano.Perú \\ ${ }^{2}$ Doctor en Salud Pública, Docente de la Universidad Andina Néstor Cáceres Velásquez, REGINA-CONCYTEC Doctora en \\ Salud Pública, Especialista en Rehabilitación Oral, Docente de la Universidad Nacional del Altiplano.Perú \\ ${ }^{3}$ Doctor en Salud Pública, Especialista en Periodoncia e Implantología Oral, Docente Principal de la Universidad Nacional \\ del Altiplano.Perú \\ ${ }^{4}$ Doctor en Salud Pública, Especialista en Cirugía Buco Maxilo Facial, Hospital Regional Cuzco.Perú \\ ${ }^{5}$ Doctor en Odontología, Especialista en Endodoncia, Docente de la Universidad Andina Néstor Cáceres Velásquez.Perú \\ ${ }^{6}$ Odontólogo Universidad de Cuenca.Ecuador \\ *luzdomingamac@hotmail.com
}

\begin{abstract}
Resumen
OBJETIVO. Los linfocitos (B y T), células NK, son las células principales de la respuesta inmunológica y del sistema de complemento. Por ello la importancia de conocer el sistema inmunitario de los seres humanos, tanto el innato como adaptativo, que son perfectamente relacionados y aplicables a la investigación y comprensión de prácticamente todos los procesos, fisiológicos y patológicos.
\end{abstract}

Palabras clave: sistema immunológico, linfocitos B, linfocitos T, células NK, activación de complemento.

\begin{abstract}
OBJECTIVE. Lymphocytes (B cells and T cells), NK cells, are the main cells of the immune response and the complement system. That is why it is important to know the immune system of both innate and adaptive mammals, which are perfectly related and applicable to the research and understanding of practically all physiological and pathological processes.
\end{abstract}

Key words: immunological system, B lymphocytes, T lymphocytes, NK cells, complement activation.

\section{INTRODUCCIÓN}

La respuesta inmune en las patologías odontológicas, sean estas de naturaleza infecciosa, traumática, neoplásica, han motivado a buscar una nueva línea de investigación como es la terapia biológica o inmunitaria contra cáncer de cabeza y cuello. Debido a la escasa existencia de este tipo de estudios en nuestro medio y a la necesidad de encontrar un método alternativo de las terapias tradicionales para obtener mejores resultados clínicos y en la calidad de vida de los pacientes, es importante adquirir conocimientos del sistema inmunitario adquirido. La palabra inmune etimológicamente esta asociada a un mecanismo de protección. El término en la antigüedad fue aplicado para referirse a personas que sufrieron de alguna enfermedad infecciosa como peste y viruela, quedando propensos a ataques posteriores. De esta manera el sistema inmune actúa como un órgano receptor periférico que transmite información al cerebro relacionada con respuestas a estímulos antigénicos externos e internos, Blalock y Smith ante esta función denominaron al sistema inmune como "el sexto sentido". ${ }^{1}$ El sistema inmune es un conjunto de tejidos, células y moléculas que integran una respuesta, de naturaleza defensiva y producida ante un agente exógeno o endógeno, que resulta extraño al organismo, denominado antígeno (Ag). Esta respuesta es conocida como respuesta inmune. ${ }^{2}$ Los organismos multicelulares detectan patógenos y responden con mecanismos de inmunidad natural. Los vertebrados tienen mecanismos adicionales que incluyen a los linfocitos, detectan antígenos específicos, generando memoria inmunológica; estos mecanismos corresponden a la inmunidad adaptativa o específica. ${ }^{2}$ Los receptores tipo inmunoglobulina de las células NK (en inglés, Killer Immunoglobulin-like Receptor, KIR) son un conjunto de proteínas de superficie cuyos ligandos principales son moléculas de clase I del complejo principal de histocompatibilidad (en inglés, Major Histocompatibility Complex, MHC). La actividad efectora de 
las células NK, está regulada por el balance entre señales de activación y de inhibición como resultado de la expresión de moléculas KIR con diferentes propiedades funcionales y de los genotipos HLA. ${ }^{3}$ El sistema de complemento es un sistema funcional de proteínas plasmáticas y proporciones pequeñas de proteínas de membrana que participan unas con otras de forma ordenada en muchas funciones de la inmunidad natural y adquirida. Se conocen más de 30 proteínas que se activan secuencialmente unas con otras a través de tres vías fundamentales de activación: vía de las lecitinas, vía clásica y vía alternativa. Entre sus funciones está la lisis de bacterias y virus, participar en los procesos inflamatorios, facilita la quimiotaxis y la vasodilatación, opsonización de antígenos, neutralización de virus, y solubilización de inmunocomplejos. ${ }^{4}$ El objetivo fue revisar la evidencia científica y ampliar conocimientos sobre el sistema inmune de los seres humanos, tanto innato como adaptativo, y que son perfectamente aplicables a la investigación y comprensión de prácticamente todos los procesos, ya sea fisiológicos como patológicos que ocurren en el sistema estomatognático humano.

\section{CÉLULAS DE SISTEMA INMUNOLÓGICO AD- QUIRIDO}

Esta división del sistema inmunológico está conformada por tres tipos de células: las células presentadoras de antígenos, linfocitos B y linfocitos T. Los linfocitos B conocidos también como células B son las encargadas de producir anticuerpos en la inmunidad humoral; las células denominadas también linfocitos $\mathrm{T}$, tienen como función activar a los linfocitos B en la inmunidad. ${ }^{1}$ Las células presentadoras de antígenos, no responden a un antígeno especifico siendo esta la principal diferencia de los linfocitos, pero estas células presentadoras juegan un papel esencial auxiliar en la respuesta inmunitaria.

\section{RESPUESTA INMUNOLÓGICA HUMORAL}

El bazo o algún ganglio linfático es el lugar donde se produce el encuentro entre el linfocito y el antígeno, si la unión del antígeno es con un linfocito B comienza la respuesta inmunológica humoral en la cual se producirán anticuerpos. En la respuesta humoral se incluyen los siguientes procesos:

1) Activación del linfocito contactado por el antígeno.

2) Crecimiento y rápida clonación repetida para formar células iguales a la iniciadora del proceso.

3) Diferenciación de las células clonadas en células plasmáticas.

4) Permanencia de un remanente de células clonadas que se convierten en células de memoria.

\section{SELECCIÓN CLONAL Y DIFERENCIACIÓN DE} LAS CÉLULAS B

El linfocito B es activado para completar la diferenciación cuando el antígeno se enlaza con sus receptores superfi- ciales a los receptores adyacentes. El antígeno se interioriza por el proceso de endocitosis, la activación estimula a las células B a crecer, dividirse rápidamente generando gran cantidad de células iguales a sí mismas con receptores específicos a un antígeno, estas células se denominan clon, el antígeno tiene la capacidad de escoger al linfocito con los receptores que sufrirá la selección clonal. Las células del clon en su gran mayoría se convierten en células plasmáticas efectoras de la secreción de anticuerpos para la respuesta humoral, y una cantidad limitada de anticuerpos. ${ }^{2}$ Los anticuerpos circulan en la sangre o la linfa como moléculas receptoras, en el lugar donde encuentran a un antígeno lo destruyen por un mecanismo innato o adquirido. Las células clonales no diferenciadas en células plasmáticas reciben la denominación de células memoria capaces de producir repuesta humoral al encontrarse nuevamente con el mismo antígeno. ${ }^{3}$

\section{MEMORIA INMUNOLÓGICA}

Al producirse un nuevo contacto con el antígeno se genera una respuesta inmunológica secundaria que se caracteriza por ser rápida, prolongada y efectiva debido que el sistema inmunológico reconoce al antígeno ocasionando que las células de memoria estén preparadas. El resultado de estas células de memoria, es lo que se conoce como memoria inmunológica, las células memoria pueden permanecer largos periodos en los seres humanos y pueden durar toda la vida manteniendo la capacidad de respuesta secundaria. ${ }^{3}$

\section{INMUNIDAD HUMORAL ACTIVA Y PASIVA}

La inmunidad humoral activa es producida cuando los linfocitos B encuentran un antígeno provocando la respuesta inmunológica, este proceso cosiste en generar anticuerpos contra el antígeno. ${ }^{4}$ La inmunidad activa, adquirida naturalmente, es aquella que se obtiene durante una infección viral o bacteriana. ${ }^{4}$ La inmunidad adquirida artificialmente, es aquella que es proporcionada por medios como vacunas, que se encargan de producir "imprimación" a la respuesta inmunológica. ${ }^{4}$ Las vacunas están conformadas por patógenos muertos o atenuados cuya finalidad es disminuir los síntomas y malestares propios de la enfermedad que se desarrollan en la respuesta inmunológica primaria. Los antígenos debilitados proporcionan los determinantes antigénicos funcionales que son tanto inmunogénicos como reactivos. El mecanismo de acción de las vacunas consiste en la acción que ejerce sobre los linfocitos $\mathrm{T}$, acelerando las defensas de las células $\mathrm{B}$, formando anticuerpos con protección inmediata, pero con el establecimiento de una memoria inmunológica pobre. ${ }^{4} \mathrm{La}$ inmunidad humoral pasiva difiere de la activa en el grado de protección y la fuente de antígenos que produce, debido que las células provienen del suero sanguíneo de un donador inmune. ${ }^{4}$ Similar a la inmunidad activa. La pasiva puede ser clasificada en:

- Naturalmente adquirida: es aquella que se trasmite a través de la placenta desde la madre al feto. Ocasionando 
que el infante este protegido ante aquellos antígenos que a la madre estuvo expuesta durante el periodo de gestación.

- Artificialmente adquirida: se adquiere al ser inyectad por sueros como gamma globulina, otros sueros se inyectan en mordeduras venenosas, botulismo, rabia y tétanos. ${ }^{4}$

\section{LINFOCITOS}

Son células sanguíneas con la función de reconocer y diferenciar los diferentes antígenos en respuesta ante un agente nocivo ${ }^{1}$ Los linfocitos provienen de la médula roja de los huesos, después de los neutrófilos constituyen el número de células más numerosas en la circulación el $75 \%$ corresponde a los linfocitos T de ayuda (Th, CD4); el $25 \%$ restante corresponde a los linfocitos B y NK. ${ }^{4}$

\section{LINFOCITOS T}

Estas células maduran en el timo, la principal función de este grupo celular es la respuesta adaptativa celular. Su receptor es el CD4 y ejerce su función a través de las citosinas; de acuerdo al tipo de citosinas se subdividen en Th: 1,2 y 3 .

- Th1. Produce: IL-2 e interferón gamma IFN- $\gamma$, su función es activar a los linfocitos y a los macrófagos, participando en la respuesta celular.

- Th2. Produce: IL-4, 5, 6, 9 y 13; entre otras, estas intervienen en la generación de anticuerpos, involucrándose en el proceso de la respuesta humoral.

- Th3. Produce el factor transformante de crecimiento TGF- $\beta$, en el tubo digestivo favoreciendo la tolerancia, regulando mecanismos de inflamación, la actividad de linfocitos y la cicatrización. ${ }^{2,6}$

TC. Expresa el receptor CD8 y es citotóxica por el daño que produce a través de las enzimas que secreta, ya que induce, la apoptosis celular. Produce pequeñas cantidades de citosinas y según el tipo que secreta se subdivide en TC1 y TC2.

$\mathrm{T} \gamma \delta$. Denominada también con el nombre de linfocito intraepitelial y puede expresar CD8; se localiza en tubo digestivo y piel, donde secreta entre otras citocinas, factor estimulante de crecimiento de queratinocitos, su función es favorecer en el proceso de cicatrización. El tipo 1 produce IFN- $\gamma$ en su mayoría, la principal función es activar macrófagos y la función de TH1, el tipo 2 secreta IL-4 que favorece la actividad de $\mathrm{TH} 2$. $^{2,6}$

TCD4-CD25. Este grupo celular posee funciones supresoras, las que realiza a través de las citocinas que secreta: TGF $\beta$ e IL-10 y de la escurfina, proteína codificada por el gen FoxP3, logrando la inhibición de la transcripción e inactivación a las células T. Existen dos tipos:

- Cooperadores: que se caracterizan por liberar sustancias químicas denominadas linfoqinas, responsables de la activar la respuesta inmune.
- Citotóxicos o supresores: responsables de producir la lisis a los agentes tóxicos. ${ }^{2,6}$

\subsection{LINFOCITOS B}

Son las células encargadas de la activación de la inmunidad adaptativa humoral, maduran en la médula espinal, secretan inmunoglobulinas que neutralizan al antígeno y activa el sistema de complemento B-1.2,6

\subsection{MADURACIÓN COMO CÉLULA B O CÉLULA T}

El proceso de maduración de célula $\mathrm{B}$ o célula $\mathrm{T}$ varía según el lugar de maduración, los linfocitos T desarrollan este proceso en dos o tres días en el timo, lugar donde los linfocitos inmaduros se multiplican constantemente pero solo sobreviven aquellos con capacidad de reconocer antígenos extraños. ${ }^{1,4}$ La selección negativa ocurre en la médula del timo durante la etapa fetal, produciéndose una destrucción de linfocitos desorientada, importante para evitar una reproducción errónea de células que ataquen a los propios tejidos del organismo. ${ }^{1,4}$ Los linfocitos que se enlazan débilmente con los autoantígenos y no provocan una reacción de activación fuerte, continúan desarrollándose, proceso que se conoce como selección positiva y se lleva a cabo en la corteza del timo. ${ }^{1,4}$ La selección positiva escoge a los linfocitos mejores dotados en reconocer las células propias adquiriendo inmunocompetencia. ${ }^{5}$ Los linfocitos B se hacen inmunocompetentes y tolerantes a los autoantígenos en la médula de los huesos, no se conoce muchos de este proceso en los humanos, pero se sabe que algunas células auto-reactivas resultan inactivadas, fenómeno conocido como anergia, mientras otras son absolutamente destruidas..$^{5}$ Cuando los linfocitos, T o B hayan adquirido la capacidad de inmunocompetencia, poseen un receptor en sus superficies, y están habilitados para reconocer y enlazarse a un determinante antigénico específico. Una vez que los receptores aparecen, el linfocito está comprometido a reaccionar con solo un antígeno ya que todos los receptores son iguales. ${ }^{1}$ Después de convertirse en inmunocompetentes, los linfocitos $\mathrm{T}$ y $\mathrm{B}$ se dirigen a los ganglios linfáticos, el bazo y otros órganos linfáticos para que se encuentren con los antígenos de esa forma, cuando reconozcan a los antígenos, completen su diferenciación a células inmunológicas completamente funcionales o sea a células B o T maduras y activadas contra el antígeno. ${ }^{1,4}$

\section{CÉLULAS PRESENTADORAS DE ANTÍGENOS}

La función de estas células en el sistema inmune es disminuir a las partículas extrañas de modo que no pueden ser reconocida por las células $\mathrm{T}$, existen diferentes tipos de células presentadoras de antígenos:

- Las células dendríticas, entre las que están las células intersticiales del tejido conectivo presente en todo el cuerpo.

- Las células de Langerhans de la epidermis de la piel. 
- Los macrófagos, que están distribuidos ampliamente a lo largo de los órganos linfáticos y los tejidos conectivos y tienen la tendencia de mantenerse fijos, como a la espera de que los antígenos lleguen a ellos. ${ }^{7}$

Todas las células vinculadas con la división adquirida del sistema inmunológico, linfocitos y CPA, están localizadas en lugares estratégicos para encontrar y procesar los antígenos actuando como centinelas. Además de su trabajo como CPA las células dendríticas y los macrófagos segregan proteínas solubles que activan las células $\mathrm{T}$. La interacción entre los linfocitos, y las células presentadoras de antígenos está subyacente en casi todas las fases de la respuesta inmunológica. ${ }^{7}$ Los linfocitos y las células presentadoras de antígenos que están en las amígdalas actúan principalmente contra los microorganismos que invaden las cavidades oral y nasal, mientras que el bazo funciona como un filtro que atrapa los antígenos del torrente sanguíneo. 7 Este sistema inmune sólo se activa cuando el organismo ha sido expuesto al agente y éste comienza a diseminarse por el organismo. ${ }^{7}$

\section{CÉLULAS NK (Natural Killer)}

Este grupo celular se desarrolla de un progenitor celular CD34+ en la médula ósea, ${ }^{8-10}$ debido a la similitud de sus fenotipos a nivel de membrana celular, se considera que los linfocitos $\mathrm{T}$ y las NK son producidas de la diferenciación a partir de un linaje ancestral similar a una NK, teniendo como característica la ausencia del complejo TCR, la mejor forma de distinguir ambos linajes modernos. ${ }^{11}$ Las células NK poseen una variedad de receptores para permitir el reconocimiento e interacción con moléculas de clase I del complejo principal de histocompatibilidad (MHC), después de la producción de estímulos las NK elaboran gran variedad de receptores de superficie y sus interacciones son destinadas de manera preferente pero no exclusiva hacia células hematopoyéticas, siendo las células dendríticas las más frecuentes. ${ }^{11,12}$

\section{CÉlULAS ACCESORIAS O PRESENTADORAS DEL ANTÍGENO}

La función de este tipo de células es eliminar al antígeno a través de la fagocitosis. Este grupo celular se encuentra representado por macrófagos y neutrófilos encargados de la fagocitosis; de basófilos que secretan mediadores químicos de la inflamación y eosinófilos que destruyen parásitos y participan de la reacción alérgica. ${ }^{13}$ Los macrófagos provienen de los monocitos y son las células principales en la inflamación crónica, su tiempo de vida oscila desde meses hasta años. Al liberarse los monocitos de los capilares sanguíneos se localizan en los tejidos transformándose en macrófagos. ${ }^{13}$

\section{SISTEMA DE COMPLEMENTO}

El sistema del complemento "es un sistema funcional de proteínas plasmáticas y de proteínas de membrana que interaccionan unas con otras produciendo funciones efectoras de la inmunidad humoral de la inflamación". ${ }^{14,16,17}$ La denominación como proteínas del complemento surgió a medida que se descubrieron las proteínas sin tener en cuenta su secuencia de activación; durante la actuación de la cascada enzimática se generan segmentos de tamaños diferentes, el de mayor tamaño se designa con la letra $b$ y el de menor con la letra a. Los dos fragmentos resultantes tienen actividades biológicas diferentes. ${ }^{18} \mathrm{El}$ sistema complemento posee una serie de propiedades que capacitan para funcionar eficazmente en la defensa contra elementos extraños sin alterar los tejidos normales y aumenta su concentración en el plasma durante la infección, por lo que se usa en el diagnóstico clínico de enfermedades infecciosas, ${ }^{19}$ ante un proceso infeccioso se activa y luego de su activación, se generan péptidos con notable actividad proinflamatoria y opsonizante, además de la formación del complejo de ataque a membrana con acción lítica directa. ${ }^{20}$

\section{ACTIVACIÓN DEL COMPLEMENTO}

Es necesario la formación y activación de proteasas C3 y C5 convertasas para llevar a cabo las funciones del sistema de complemento. Se conocen tres vías para la activación de C3 convertasa: la vía clásica, la alternativa y la de las lectinas. En las distintas rutas de activación se originan péptidos que participan en la inflamación. Algunos componentes del sistema complemento se activan al unirse a la superficie de agentes infecciosos en ausencia de anticuerpos, como ocurre en la vía de las lectinas y la vía alternativa, al reconocer moléculas extrañas, proteínas o carbohidratos, en la superficie de los agentes patógenos. La vía alternativa se inicia al unirse espontáneamente un componente activado del complemento a la superficie del patógeno. En cada una de las tres vías intervienen un conjunto de proteínas del complemento diferentes. ${ }^{21}$ Se puede considerar una cuarta vía a partir de C5 que conlleva a la etapa final que es la lisis. $^{18,21}$

\section{CONCLUSIÓN}

Una vez realizada la revisión bibliográfica se concluye:

- La inmunidad adquirida o adaptativa establece una protección efectiva del hospedero contra los microorganismos patógenos, cuando éstos han evadido o resistido los mecanismos innatos de defensa.

- Además, el sistema inmunitario posee otras funciones como eliminar el agente infeccioso, otorgando protección al hospedero contra la reinfección por el mismo agente, garantizando esta acción debido a la existencia de una gran población de células de memoria.

\section{Referencias}

1 LaRosa D, Orange J. Lymphocytes. J Allergy Clin Immunol 2008; 121: 364-9. 
2 Askenasy N, Kaminitz A, Yarkoni S. Mechanisms of T regulatory cell function. Autoimmun Rev 2008; 7: 370-375.

3 Reinhardt L, Kang S, Liang H, Locksley R. T helper cell effector fates- who, how and where? Curr Opin Immunol 2006; 18:271-277.

4 Parham P. Inmunología. 2a edición, Ed. Médica Panamericana.Buenos Aires, Argentina 2006.

5 Weaver C, Harington L, Mangan P, Gavriell M, Murphy K.Th17: An effector CD4 T cell lineage with regulatory $\mathrm{T}$ cell ties. Immunity 2006; 24: 677-688.

6 Youinou P. B cells conducts the lymphocyte orchestra. J Au-toimmun 2007; 28: 143-151.

7 Bosco N, Kirberg J, Ceredig R, Agenes F. Peripheral T cells in the thymus: have they just lost their way or do they do some-thing? Immunol Cell Biol 2009; 87(1): 50-57.

8 Karimi M, Cao TM, Baker JA, Verneris RM, Soares L, Negrin RS. Silencing human NKG2D, DAP10, and DAP12 reduces cytotoxicity of activated CD8+ T cells and NK cells. J Immunol 2005;175:7819-7828.

9 Kelley J, Walter L, Trowsdale J. Comparative genomics of natural killer cell receptor gene clusters. PLoS Genetics 2005;1:129-139.

10 O'Connor GM, Hart OM, Gardiner CM. Putting the natural killer cell in its place. Immunology 2006;117:1-10.

11 Parham P. MHC class I molecules and KIRs in human history, health and survival. Nat Rev Immunol 2005;5:201214.

12 Lodoen M, Lanier L. Natural killer cells as an initial defense against pathogens. Curr Opin Immunol 2006; 18: 391-398.

13 Galkina, E., Ley, K., "Immune and inflammatory mechanism of atherosclerosis", Annu. Rev. Immunol., 2009, 27, 165-197.

14 Ibáñez E, Pareja E. Curso de inmunología general [Internet]. 2010 [citado 14 Mar 2011] [aprox. 4 pantallas].

15 García A, Alonso M, Peña J. Sistema del complemento [Internet]. 2008 [citado 14 Mar 2011] [aprox. 2 pantallas].

16 Salgado H, Montoya JC, López J, Patiño P. Guía de estudio y manejo del paciente sospechoso de presentar alteraciones en el sistema del complemento [Internet]. 2008 [citado 7
Jul 2011] [aprox. 3 pantallas].

17 Carroll M. The complement system in regulation of adaptive immunity. Nat Immunol. 2008, 5: 981-6.

18 Asencio LP. Importancia del sistema de complemento. Rev Med Vallejiana. 2007; 4(1):2-10.

19 Medicina Molecular. Complemento [Internet]. 2007 [citado 10 Mar 2011] [aprox. 2 pantallas].

20 Atlas de Inmunología. Respuesta inmune frente a bacterias extracelulares [Internet]. 2009 [citado Mar 2011] [aprox. 4 pantallas].

21 Kunkel, D. Microbiology and immunology [Internet]. 2006 [citado 10 Mar 2011] [aprox. 2 pantallas].

Recibido: 29 de enero de 2018.

Aceptado: 17 de marzo de 2018. 
